\title{
TORTICOLLIS SECONDARY TO A POSTERIOR FOSSA TUMOR: A CASE REPORT
}

\author{
Aslı Göztepe ${ }^{1}$, Mahmut Alper Güldağ ${ }^{1}$, Ahmet Tolgay Akıncr² ${ }^{2}$ Mert Çiftdemir ${ }^{3}$, \\ ${ }^{1}$ Trakya University School of Medicine, Edirne, TURKEY \\ ${ }^{2}$ Department of Neurosurgery, Trakya University School of Medicine, Edirne, TURKEY \\ ${ }^{3}$ Department of Orthopedics and Traumatology, Trakya University School of Medicine, Edirne, TURKEY
}

\begin{abstract}
Aims: Torticollis secondary to a posterior fossa tumor is a rare condition that is mostly seen in pediatric patients. In this case report, it is aimed to present a 23-month-old male patient with a posterior fossa tumor that presents the symptoms of torticollis. Case Report: A 23-month-old male patient was admitted to the hospital with a history of a restricted range of motion in his neck and leaning to his left side while sitting. Physical examination of the patient revealed acute onset of atlantoaxial rotatory subluxation findings therefore, the initial diagnosis was Grisel's Syndrome. Later, a cranial magnetic resonance imaging revealed a mass which was seen in the posterior fossa. The mass was considered as the cause of the torticollis. Conclusion: This case report shows the importance of the differential diagnosis of torticollis. Posterior fossa tumors should not be overlooked while searching for the cause of torticollis. Keywords: Torticollis, posterior fossa tumors, infratentorial neoplasms
\end{abstract}

\section{INTRODUCTION}

Torticollis is generally a pediatric pathology that can be congenital or acquired. Various pathologies can lead to acquired torticollis (1). It is originated from sternocleidomastoideus muscles on the neck (1). Acquired torticollis can be seen due to ligamentous, osseous, muscular, neurological and many other pathologies. However rarely, it could present secondary to posterior fossa and cervical spinal tumors (2).

23 month-old child with torticollis secondary to a posterior fossa tumor, which was diagnosed at first as Grisel's syndrome was reported in this case report. The aim of this report is to attract attention to the acquired torticollis that presents with posterior fossa tumors since it can easily be overlooked by the physicians.

\section{CASE REPORT}

A 23-month-old male patient was admitted to the pediatric clinic of the Trakya University School of Medicine with the complaint of limitation in neck movements. After the physical examination performed in the pediatric clinic, the patient was referred to the orthopedics and traumatology clinic with a pre-diagnosis of atlantoaxial rotatory subluxation (AARS) or Grisel's syndrome. The physical examination performed in the orthopedics clinic revealed that his head was deviated to the left, rotated to the right and his left gaze was limited. The patient had an upper respiratory tract infection history about 15 days before admitting to the clinic. He had a high fever, and his complaints were decreased with antibiotic treatment. This information had increased the suspicion of Grisel's syndrome. Muscle relaxant therapy and 500 grams of mento-occipital halter traction were applied. A radiological examination of the atlantoaxial joint was performed. The patient's treatment 
continued with increasing the weights 250 grams each day for 5 days, but his symptoms did not improve. Therefore, the patient underwent cranial computed tomography and a mass pressuring the $4^{\text {th }}$ ventricle was seen. After the observation of the mass, the case was referred to the Neurosurgery Department of Trakya University School of Medicine.

The systemic examination at the neurology clinic did not reveal any pathology. The general condition of the patient was found to be good. His daily behaviors and neurological examination were normal. The pupils were isochoric, the globe movements were natural, and all of the four limbs were active. Also, no facial asymmetry was detected.

Cranial magnetic resonance imaging (MRI) revealed a mass in the right cerebral hemisphere at the level of the middle cerebellar peduncle, which contained cystic areas, expanding towards the foramen magnum direction. The mass had a restricted diffusion, and significant hypointensities that indicate calcification and pressure from the right lateral aspect. Therefore, removal of the mass was deemed suitable for the patient.

The tumor was removed from the patient and was sent to the medical pathology laboratory. The pathological examination revealed the tumor was malignant and composed of slightly differentiated cells. Common INI-1 immune secretion loss was detected.

After the operation, the patient was admitted to the intensive care unit for follow-up. The patient did not have any additional complaints; therefore, his hospitalization continued at the neurosurgery service.

The patient was evaluated in the pediatric hematology-oncology-radiology-neurosurgery council and it was decided to discharge the patient. Whole-body and cranial MRI was recommended. Postoperative structural changes and hemorrhagic products were observed in MRI. In addition, a residual lesion with contrast enhancement, which was thought to belong to the inferior component of the mass, was observed. However, there was no significant change in other findings.

After the last evaluation of the patient, all findings were found to be normal and age-appropriate. The patient, who did not have any additional complaints, was discharged.

\section{DISCUSSION}

Atlantoaxial rotatory subluxation is a dislocation of the C1-C2 joint that develops after unilateral injury of the transverse ligament which is characterized by patients' complaints about widespread neck pain (3). The most important symptom of torticollis is that the head turns to one side. In addition, tenderness or pain is felt in the neck and shoulder muscles (4). Torticollis attacks in infants may be accompanied by other symptoms such as vomiting, irritability, and drowsiness. Subsequent torticollis usually results from trauma or reaction to drugs and is considered as an acute condition. Many reasons may cause acute torticollis and usually, the anamnesis of the patient takes the physician to the specific diagnosis. Some medications can cause sudden involuntary contractions of the neck, face or upper back muscles. It may consist of some prescription drugs or addictive substances such as cocaine and amphetamines. Taking such drugs is considered a risk factor for torticollis (5). However, the age of our patient with acute torticollis eliminates some of these reasons.

Infection is another cause of torticollis. Infections frequently affect the lymph nodes and this may cause the spasm in the muscles directly above these structures (5). In this case, the infection was the most important factor that made physicians think about Grisel's syndrome since the patient had a recent history of upper respiratory tract infection.

Other causes of torticollis include wounds, tumors, and neck arthritis similar to our case.

It is thought that acquired torticollis does not frequently present secondary to a posterior fossa tumor. However, in the study of Fąfara-Leś et al. (6) it is discovered that approximately 1 out of 5 patients presenting with torticollis had a central nervous system tumor. Amongst these cases, exactly 10 out of 12 had a tumor located in the posterior cranial fossa (6). Although the incidence of the disease is not very rare, it can often be overlooked because its symptoms are difficult to distinguish.

Our patient did not present only with torticollis, but also he had bilateral pupil edema. But not all of the patients have such a variety of symptoms. In the series of case reports of Turgut et al. (7) patients had no other symptoms but torticollis secondary to posterior fossa tumor. Therefore, physicians should always be considering posterior fossa tumors in their differential diagnosis.

In the case report of Choi et al. (1) posterior fossa tumor was overlooked for one month after the initial visit and the treatment was impeded. In our case, it was 
also first thought as secondary to other pathologies such as Grisel's syndrome and posterior fossa tumor was overlooked. However, the patient was correctly diagnosed and treated before the disease reached a form that would cause permanent damage.

In the case series of Ouattassi et al. (8) it is seen that acute febrile torticollis could present secondary to an infectious cause. Two out of three of their cases had a history of an infectious pathology like febrile odynophagia (8). Our case also had a history of an upper respiratory tract infection approximately fifteen days ago. Thus, it is seen that infectious causes are more likely the cause of acute febrile torticollis, not posterior fossa tumors.

In conclusion, physicians should not overlook posterior fossa tumors in their differential diagnosis while trying to find the cause of the torticollis because posterior fossa tumors can be highly lethal and should be treated immediately.

\section{Ethics Committee Approval: N/A}

Informed Consent: Written informed consent was obtained from the patient's family for this study.

Conflict of Interest: The authors declared no conflict of interest. Author contributions: Concept: MAG, AG, MC. Supervision: MAG, AG, MC. Resources: MAG, AG, MC. Materials: MAG, AG, MC. Data collection and/or processing: MAG, AG, MC. Analysis and/ or Interpretation: MAG, AG, MC. Literature Search: MAG, AG, MC . Writing Manuscript: MAG, AG, MC. Critical Review: MAG, AG, MC.

Financial disclosure: The authors declared that this study received no financial support

Editor-in-chief's Note: Two of the authors of this article, Asli Göztepe and Mahmut Alper Güldağ are members of the editorial board of Turkish Medical Student Journal. However, they did not take place in any stage on the editorial decision of the manuscript. The editors who evaluated this manuscript are from other institutions

\section{REFERENCES}

1. Choi HY, Son S, Jo HS et al. An infant with cerebellar tumor presenting with torticollis as the only initial symptom. Neurology Asia 2015;20(4):401-3.

2. Kumandaş S, Per H, Gümüş H et al. Torticollis secondary to posterior fossa and cervical spinal cord tumors: report of five cases and literature review. Neurosurg Rev 2006;29(4):333-8.

3. Ciftdemir M, Çopuroğlu C, Özcan M et al. Non-operative treatment in children and adolescent with atlantoaxial rotatory subluxation. Balkan Med J 2012;29(3):277-80.
4. Aladağ Çiftdemir N, Eren T, Çiftdemir M. A rare cause of torticollis: Grisel syndrome. J Trop Peiatr 2018;64(3):245-8.

5. Tomczak KK, Rosman NP. Torticollis. J Child Neurol 2013;28(3):365-78.

6. Fąfara-Leś A, Kwiatkowski S, Kawecki Z et al. Torticollis as a first sign of posterior fossa and cervical spinal cord tumors in children. Childs Nerv Syst 2014;30(3):425-30.

7. Turgut M, Akalan N, Bertan V et al. Acquired torticollis as the only presenting symptom in children with posterior fossa tumors. Childs Nerv Syst 1995;11(2):86-8.

8.Ouattasi N, Chmiel M, Kerouiti ZE. Acyte febrile torticollis in youth: clinical investigation and current management. Pan Afr Med J 2015;21(1):163. 